\title{
Self-Concept, Self-Esteem and Psychopathological Symptoms in Persons with Intellectual Disability
}

\author{
Maite Garaigordobil and José Ignacio Pérez \\ Universidad del País Vasco
}

\begin{abstract}
The purpose of this study is two-fold: (a) to analyze self-concept, self-esteem, and psychopathological symptoms in individuals with and without intellectual disability; and (b) to explore whether there were gender differences in these same variables in both groups. The sample is made up of 170 participants aged 19 to 40, 128 without disability and 42 with intellectual disability. The methodology is descriptive. To measure the variables, three assessment instruments were applied: the "Listado de adjetivos para la evaluación del autoconcepto en adolescentes y adultos" (LAEA; Garaigordobil, in press), the Rosenberg Self-Esteem Scale (RSE; Rosenberg, 1965), and the Revised Symptom Checklist-90 (SCL90; Derogatis, 1983). The ANOVA showed that participants with intellectual disability scored significantly lower in self-concept and self-esteem, and higher in all the psychopathological symptoms except for somatization. The ANOVA did not reveal significant gender differences in any variables in either of the two groups.

Keywords: intellectual disability, self-concept, self-esteem, psychopathology
\end{abstract}

\begin{abstract}
El estudio tuvo dos objetivos: (a) analizar el autoconcepto, la autoestima y diversos síntomas psicopatológicos en personas con y sin discapacidad intelectual; y (b) explorar la existencia de diferencias de género en autoconcepto, autoestima y síntomas psicopatológicos en ambos grupos. La muestra está configurada con 170 participantes de 19 a 40 años, 128 sin discapacidad y 42 con discapacidad intelectual. El estudio empleó una metodología descriptiva. Para medir las variables se aplicaron tres instrumentos de evaluación: "Listado de adjetivos para la evaluación del autoconcepto en adolescentes y adultos" (LAEA; Garaigordobil, en prensa), la Escala de Autoestima de Rosenberg (EA; Rosenberg, 1965), y el Listado de Síntomas-90-Revisado (SCL-90-R; Derogatis, 1983). Los resultados del ANOVA muestran que las personas con discapacidad intelectual obtenían puntuaciones significativamente inferiores en autoconcepto y autoestima, así como superiores en todos los síntomas psicopatológicos excepto en somatización. Los ANOVAs no evidencian diferencias de género en ninguna variable tanto en el grupo con discapacidad intelectual como en el grupo sin discapacidad.

Palabras clave: discapacidad intelectual, autoconcepto, autoestima, psicopatología
\end{abstract}

This work was financed by the Vicerrectorado de Investigación de la Universidad del País Vasco (1/UPV 00006.231-H-15910/2004).

Correspondence concerning this article should be addressed to Maite Garaigordobil, Facultad de Psicología, Universidad del País Vasco, Avda. de Tolosa 70, 20018 San Sebastián. (Spain). Phone: 943-015634. Fax: 943-015670. E-mail: maite.garaigordobil@ehu.es

Translation: Virginia Navascués Howard 
The American Association on Mental Retardation (AAMR) indicates in the $10^{\text {th }}$ and last edition of the handbook Mental Retardation: Definition, Classification, and Support Systems (AMMR, 1992) that "Mental retardation is a disability characterized by significant limitations both in intellectual functioning and in adaptive behavior as expressed in conceptual, social, and practical adaptive skills. This disability originates before the age of 18" (Luckasson et al., 2002). Despite the conservatism of the AAMR, which maintains the traditional expression of mental retardation, this new formulation opens the door to the concept of intellectual disability, extensively used at present because it does not resort to a simple linear relation with IQ, but to a more complex model in which disability can have different origins and require different resources and adaptations, different supports, in the terminology of the AAMR (resources and strategies to promote the person's development, education, interests, and personal wellbeing and that improve individual functioning). For some years, many countries have been using the term intellectual disability; moreover the International Classification of Discapacity of the World Health Organization (WHO, 2001) also proposes the use of this term. The AAMR has even been debating whether to change its name to the American Association on Intellectual Disability (Verdugo, 2003), which would doubtless help to consolidate this conceptual change once and for all.

In its new theoretical formulation, the AAMR does not use the terms borderline (IQ = 70-85), mild ( $\mathrm{IQ}=55-70)$, moderate (IQ = 40-55), severe (IQ = 25-40), and profound (IQ less than 25). Owing to the degree of acceptance of their contributions, it is likely that the use of this terminology will decline in favor of the inclusion of types, functions, and intensities of the supports required in each classification category: (a) intermittent support (administered when the individual does not need permanent support; it is episodic and can be of high or low intensity); (b) limited support (administered in a certain dimension or period; of an intensive nature); (c) extensive support (of a continuous nature and with no temporal limit and normally affecting more than one of the individual's settings); and (d) penetrating or generalized support (of a permanent nature and high intensity; it is necessary in various settings). From this viewpoint, the difference between the categories mild and borderline, for example, are diluted. Mental retardation or intellectual disability is no longer based predominantly on the IQ, insofar as adaptive skills, which become increasingly more important, are more useful to predict the supports that each person will need. Along these lines, in a recent study of the Instituto de Migraciones y Servicios Sociales (Institute of Migrations and Social Services; IMSS), it is proposed to substitute the term "persons with mildborderline intelligence" with the term "persons with intellectual disability who need intermittent support." The first part of the term-intellectual disability-acknowledges these people's difficulties to adapt to the cognitive requirements or intellectual skills of their social setting, conceptually assimilating such difficulties to the series of intellectual disabilities, whereas the second part-the need for intermittent support-indicates the minimum degree of disability with regard to the other levels of support (IMSS, 2003). Based on the opinion of professionals, members of associations, and family members of the 236 subjects with mild-borderline intellectual disability of between 0-64years of age included in this investigation, it is concluded that these persons are characterized by: (a) an appearance of normality that usually does not display their disability; this apparently advantageous fact often becomes an obstacle because they have to compete without having adequate support with people with no disability; (b) frequent lack of correspondence between their chronological age and their mental age; (c) difficulties in taking the initiative and using cognitive strategies that would allow them to solve daily problems; and (d) a process of slow learning, that requires more support and more time to reach the necessary level.

Self-concept and self-esteem are crucial variables in the study of mild-borderline intellectual disability. Investigators such as Sinanson (1992) have reported these disabled persons are often aware of the negative concept that society has of them-in which they are habitually presented as being infantile, they are ridiculed, or considered a threat-and which they can end up sharing. In contrast, social comparison plays an essential role in the development of self-esteem, as people evaluate themselves in comparison with other people. In this sense, any negative information derived from this process because of significant limitations in intellectual functioning or in any of the adaptive skills will be a threat to their self-esteem.

Studies on self-concept and self-esteem in persons with mild-borderline mental disability reveal contradictory results. In some of these studies, young and adult disabled people obtain significantly lower scores in self-concept and selfesteem than do people who are not disabled (Facchini, 1996; Long, 1997; Masi, Mucci, Favilla, \& Poli, 1999; Szivos \& Griffiths, 1990). This is not surprising if we take into account the customary limitations these people present in various conceptual, social, and practical adaptive skills. However, in other investigations, the opposite is observed, that is, an exaggerated appraisal of self-concept and self-esteem in people with mild-borderline intellectual disability ( $\mathrm{Li}, \mathrm{Tam}$, \& Man, 2006; Repetto, \& Cifuentes, 2000). In accordance, some authors emphasize that the concept that persons with mild intellectual disability have of their disability may have such a strong emotional charge that it makes them incapable of admitting and accepting their limitations. Thus, they may feel the need to protect themselves from negative appraisals and to compensate for them by excessive appraisals of their self-concept and self-esteem. Aware of their many difficulties, they may come to reject attributions of inferiority or incompetence, developing a denial mechanism (Gresham \& MacMillan, 1997; Repetto \& Cifuentes). 
The analysis of these studies leads to the consideration that the discrepancies in their results may derive from various factors such as: (a) the different methodologies or research design employed-experimental designs (Facchini, 1996; Long, 1997; Masi et al., 1999) in contrast to descriptive single case studies (Repetto \& Cifuentes, 2000); (b) the heterogeneity of the samples-some studies compare individuals with and without intellectual disabilities but without clinical disorders (Facchini; Long), whereas others analyze the differences among diverse samples, for example, people with learning problems, intellectual disability, behavioral problems, and attention deficit with hyperactivity (Gresham \& MacMillan, 1997), whereas others analyze clinical samples, for instance, adolescents and adults with depressive disorders with and without intellectual disability, (Masi et al.); (c) the diverse ages of the subjects of the study samples-children and adolescents (Long; Repetto \& Cifuentes), adultos (Facchini; Szivos \& Griffiths, 1990), adolescents and adults (Masi et al.); and (d) the diverse instruments employed to assess self-concept and selfesteem-interviews (Li et al., 2006), self-reports (Long), teachers' reports (Long), and parents' reports (Masi et al.).

Although the tendency of the results in the studies of adults (Facchini, 1996; Masi et al., 1999; Szivos \& Griffiths, 1990) has revealed lower self-concept and self-esteem in persons with intellectual disability, the purpose of the present study is to ratify that adults with intellectual disability have a significantly lower level of self-concept-self-esteem than do adults who have no disability.

The prevalence of psychopathological disorders among people with intellectual disability has been studied extensively, and the literature about the topic reveals a higher incidence of psychopathological problems in people with intellectual disability than in people without this kind of problem (Borthwick-Duffy, 1994; Clay \& Thomas, 2005; Dosen, 1993; Nezu, Nezu, \& Gill-Weiss, 1992; Rojahn \& Tasse, 1996). The level of intellectual disability is one of the main variables associated with the presence of psychopathology. Accordingly, despite the fact that some authors have found a higher incidence of these problems in the case of more severe disabilities (Clay \& Thomas), most of the investigations allow observe a higher incidence of psychopathological problems in persons with mild-borderline disability (Bouras \& Drummond, 1992; Cowley et al., 2004; LaMalfa, Notarelli, Hardoy, Bertelli, \& Cabras, 1997; Slone, Durrheim, Kaminer, \& Lachman, 1999). With regard to specific psychopathological problems, diverse studies have shown that not only in comparison with youths and adults with no intellectual disability, but also in comparison with those who present moderate or severe disability, individuals with mild-borderline intellectual disability displayed a higher incidence of anxiety disorders (Cowley et al.; LaMalfa et al.; Masi et al., 1999), somatoform disorders (LaMalfa et al.), personality disorders (Hurley, Folstein, \& Lam, 2003), depressive disorders (Cowley et al.; Lunsky, 2003; Masi et al.), a tendency to isolate themselves (LaMalfa et al.), and schizophrenia (Bouras \& Drummond; Cowley et al.).

The literature about mild-borderline intellectual disability does not provide much data about gender differences in selfconcept-self-esteem or in the psychopathological symptoms of this population. The few studies that have analyzed the existence of differences in self-esteem as a function of gender in adults with intellectual disability have found no significant differences (Facchini, 1996). Other studies with people without intellectual disability that have analyzed gender differences in self-concept and self-esteem present disparate results. Some investigations find gender differences, observing a poorer global self-concept in women (Wilgenbush \& Merrel, 1999). However, other works have found no significant differences either in self-concept (Garaigordobil, Durá, \& Pérez, 2005) or in self-esteem (Lameiras \& Rodríguez, 2003).

With regard to psychopathological symptoms, in most studies, women seem to display higher psychopathological levels, both in the global indexes and in some of the dimensions of the Symptom Checklist-90 (SCL-90; Derogatis, 1983). Specifically, in the general Spanish population, González de Rivera, De las Cuevas, Rodríguez Abuín, and Rodríguez Pulido (2002) found higher scores in women in the dimensions of somatization, depression, anxiety, phobic anxiety, as well as in the Global Severity Index, the Positive Symptom Total, and the Positive Symptom Distress Index.

The purpose of this study is twofold: (a) to analyze comparatively self-concept, self-esteem, and diverse psychopathological symptoms in persons from 19 to 40 years of age, with and without intellectual disability; and (b) to explore the existence of gender differences in selfconcept, self-esteem, and psychopathological symptoms in people with and without intellectual disability. Four hypotheses were proposed: (a) People with intellectual disability would score significantly lower in self-concept and self-esteem than persons with no disability; (b) persons with intellectual disability would obtain significantly higher scores in psychopathological symptoms in comparison to persons with no disability; (c) no gender differences would be found in self-concept and self-esteem of the participants with and without intellectual disability; and (d) women with and without intellectual disability would have higher scores in psychopathological symptoms.

\section{Method}

\section{Participants}

The sample was made up of 170 participants, ages between 19 and 40 years, from the three provinces of the Autonomous Basque Community; 128 participants had no intellectual disability and 42 participants had intellectual disability and needed intermittent support. 
The sample with intellectual disability was selected using stratified random sampling by age group (19-22, 23-30, and 31-40) from among all the users of the Ortzadar Parent's Association, an organization whose main goal is to facilitate the integration at all levels of people diagnosed with mildborderline disability in the province of Guipúzcoa. For this purpose, it promotes management, orientation, diagnosis, educational, integration and social-work insertion services, and housing and tutoring projects. It intervenes in all the situations that generate exclusion for this collective, in collaboration with all kinds of public and private institutions. Although originally, the sample of people with intellectual disability comprised 49 participants, individuals who were being attended by a psychologist were eliminated from the study because of some severe mental disorder (schizophrenia, bipolar disorder, borderline personality disorder...), so the final sample was made up of 42 persons with intellectual disability, who were receiving support because of this disability. Regarding gender, $78.6 \%$ were male $(n=33)$ and $21.4 \%$ were female $(n=9)$. This sample includes individuals with different educational levels: without any studies (4.8\%), primary studies $(90.5 \%)$, and secondary studies $(4.8 \%)$. The participants had various occupational levels: students $(26.2 \%)$ and unqualified manual workers $(73.8 \%)$. Of the sample, $85.7 \%$ were in possession of the disability certificate (36), $2.4 \%$ had solicited it and were waiting for it to be processed (1) and $11.9 \%$ did not currently have this certificate (5).

The participants without intellectual disability were randomly selected. For this purpose, the sample of a previous study carried out with 1579 individuals, from 12 to 65 years of age, in the Autonomous Basque Community from the census of the three province capitals (Bilbao, San Sebastián, and Vitoria) was used as reference. In this previous study, diverse strata were taken into account: population index in each city, gender, educational level, work status, etc. Simple random sampling was performed, eliminating the individuals who were in psychological treatment because of some mental disorder at the time of the sampling. For the current comparative study, the 128 subjects without disability were matched in certain characteristics of the sample with intellectual disability (age, studies, work status...). Of these 128 individuals, $57.8 \%$ were male $(n=74)$, and $42.2 \%$ were female $(n=54)$. The population without intellectual disability also included individuals with various educational levels: without any studies $(0.8 \%)$, primary studies $(51.6 \%)$, and secondary studies $(47.7 \%)$, as well as various occupational levels: students $(10.2 \%)$, manual workers $(74.2 \%)$, professionals and workers in intellectual activities (3.9\%), housewives $(9.4 \%)$, and unemployed people $(2.3 \%)$.

\section{Assessment Instruments}

In order to measure the dependent variables, three assessment instruments, with satisfactory values of reliability and validity, were administered: The Rosenberg Self-Esteem
Scale (RSE, Rosenberg, 1965), the "Listado de adjetivos para la evaluación del autoconcepto en adolescentes y adultos" (LAEA [Adult and Adolescent Self-Concept Adjective Checklist], Garaigordobil, in press), and the Revised Symptom Checklist (SCL-90-R; Derogatis, 1983).

LAEA. (Garaigordobil, in press). This list is made up of 57 adjectives, and respondents are requested to rate on a 5point Likert-type scale (ranging from $0=$ not at all to $4=$ very much) the degree to which these adjectives define or describe their personality. In a study carried out with a sample of 634 subjects, it obtained a Cronbach's alpha coefficient of .92 and a Spearman-Brown coefficient of .83. Test-retest reliability with a sample of 142 university students and a 40-day interval was high $(r=.83, p<.001)$, showing that the test has temporal stability. To analyze the validity of the LAEA, we calculated its correlations with other instruments that measure self-concept ("Autoconcepto, Forma-5," [Selfconcept, Form-5], AF-5; García \& Musitu, 1999) and selfesteem (the RSE, Rosenberg, 1965), obtaining significant correlations both with the AF-5 $(r=.71, p<.001)$ and the $\operatorname{RSE}(r=.63, p<.001)$, which shows construct validity.

The Rosenberg Self-Esteem Scale; RSE, Rosenberg, 1965). This scale evaluates general self-esteem with 10 statements that refer to global feelings of self-evaluation ("In general, I am satisfied with myself"), 5 of which are worded positively and 5 negatively. Respondents are requested to read the statements and rate the degree to which each one can be self-applied, on a 4-point Likert-type scale (ranging from totally agree to totally disagree). The reliability of this scale has been extensively reported in the literature. McCarthy and Hoge (1982) reported internal consistency coefficients (Cronbach's alpha) of between .74 y .77, and test-retest reliability of .63 (with a 7-month interval) and of .85 (2-week interval). The validity of the scale as a unidimensional measure of self-esteem has also been verified in various studies (Rosenberg, 1965; Silber \& Tippett, 1965).

The Revised Symptom Checklist (SCL-90-R, Derogatis, 1983). This self-report is made up of 90 items distributed in 10 psychopathological scales: Somatization (experiences of body dysfunction, with neurovegetative alterations of the cardiovascular, respiratory, gastrointestinal, and muscular systems); Obsession-Compulsion (behavior, thoughts, and impulses that the person considers absurd and undesired, and which generate intense anxiety and are difficult to resist, avoid, or eliminate); Interpersonal Sensitivity (feelings of shyness, shame, tendency to feel inferior to others, hypersensitivity to the opinions and attitudes of others and, in general, discomfort and inhibition in interpersonal relations); Depression (dysphoric experiences, anhedonia, hopelessness, impotence and lack of energy, self-destructive ideas and other cognitive and somatic characteristics of depressive states); Anxiety (clinical manifestations of anxiety, both generalized and acute or "panic," including general signs of emotional tension and its psychosomatic manifestations); Hostility (thoughts, feelings, and behaviors 
characteristic of states of aggressiveness, anger, irritability, rage, and resentment); Phobic Anxiety (persistent, irrational and exaggerated fear of an animal or person, place, object, or situation, generally complicated by avoidance or escape behaviors, with higher loadings on the agoraphobic and social phobia scales than simple phobia); Paranoid Ideation (paranoid behavior, which includes suspiciousness, selfreferential focus, and delusional ideation, hostility, grandiosity, fear of losing one's autonomy, and need for control); Psychoticism (psychotic spectrum that goes from mild schizoid to full-fledged psychosis, and which in the general population is related more to feelings of social alienation than to clinically manifest psychosis), and an Additional Scale (miscellaneous symptoms that clearly refer to melancholic depression).

A Total Symptom Score in the SCL-90-R is obtained by adding the scores in the 10 scales. Moreover, the test provides a Global Severity Index (GSI), a generalized and indiscriminate measure of the intensity of psychological and global psychosomatic suffering; a Positive Symptom Total (PST), the number of symptoms present; and a Positive Symptom Distress Index (PSDI), which relates the suffering or global distress to the number of symptoms. Results from studies conducted with a Spanish sample (González de Rivera et al., 2002) obtained satisfactory reliability and were consistent with those carried out by Derogatis (1983). The values of the alpha coefficients ranged between .81 and .90 . Internal consistency coefficients indicate that item homogeneity of each dimension is very high. Temporal stability (between .78 and .90) with a 1-week test-retest interval showed score stability over that period. Other studies by De las Cuevas and González de Rivera, (1991) also revealed the relation between the profile of symptomatic dimensions and the diagnostic group of the clinical sample (obtaining significantly higher scores in psychiatric samples than in nonclinical samples), thus reinforcing the validity of the instrument. The authors' original studies with American samples showed construct validity (Derogatis \& Cleary, 1977) and convergent validity, in view of the high correlations of the symptomatic dimensions with the MMPI in psychiatric patients (Derogatis, Rickels, \& Rock, 1976), as well as criterion or empirical validity (Derogatis).

\section{Design and Procedure}

For this study, we used descriptive methodology. The administration of the assessment instruments to the intellectually disabled participants was performed by the psychologist and social worker of the center (Ortzadar). This was carried out in small groups of 5 to 8 individuals, under constant supervision of the people who were responsible for the assessment, who solved individually any reading comprehension difficulties that arose for some of the members of this collective. The administration was carried out in a large room and the participants were sufficiently separated to guarantee total privacy of such difficulties. The assessment battery was administered to the nondisabled participants by psychologists and students trained in seminars for this purpose. The tests were administered in two 1-hour assessment sessions.

\section{Statistical Analyses}

Levene's test was conducted to verify the assumption of homocedasticity in all the variables. In some of them, unequal variances were found; therefore we performed a $t$ test for independent samples. The results of the $t$-test were identical to those found with ANOVA. Therefore, the results obtained by ANOVA are presented. The SPSS 13.0 statistical package was used.

\section{Results}

\section{Self-Concept, Self-Esteem, and Psychopathological Symptoms in Individuals with and without Intellectual Disability}

In order to compare self-concept, self-esteem, and various psychopathological symptoms in persons with and without intellectual disability (neither group having mental disorders), means and standard deviations were calculated and an ANOVA was performed, the results of which are presented in Table 1.

As can be seen in Table 1, individuals with intellectual disability, in comparison to nondisabled persons, obtained significantly lower scores in self-concept and self-esteem, as well as significantly higher scores in the psychopathological symptoms of obsession-compulsion, interpersonal sensitivity, depression, anxiety, hostility, phobic anxiety, paranoid ideation, psychoticism, and additional symptoms (melancholic depression), and in the Total Symptom Score, the Global Severity Index, and the Positive Symptom Total Score.

\section{Self-Concept, Self-Esteem, and Psychopathological Symptoms. Gender Differences in Individuals with and without Intellectual Disability}

In order to explore the existence of gender differences in self-concept, self-esteem, and psychopathological symptoms between the two groups of participants, an ANOVA was performed. The results of this ANOVA are presented in Tables 2 (people with intellectual disability) and 3 (people without intellectual disability).

As can be seen in these tables, no significant differences between men and women were obtained in any of the variables measured, that is, either in self-concept or in selfesteem, or in psychopathological symptoms. These results were confirmed in both the groups of participants (see Tables 2 and 3$)$. 
Table 1

Differences in Self-Concept, Self-Esteem, and Psychopathological Symptoms between Persons with and without Intellectual Disability

\begin{tabular}{|c|c|c|c|c|c|}
\hline \multirow[t]{2}{*}{ Variables } & \multicolumn{2}{|c|}{$\begin{array}{l}\text { With intellectual disability } \\
\qquad(n=42)\end{array}$} & \multicolumn{2}{|c|}{$\begin{array}{l}\text { Without intellectual disability } \\
\qquad(n=128)\end{array}$} & \multirow[t]{2}{*}{$\begin{array}{l}\text { ANOVA } \\
F(1,168)\end{array}$} \\
\hline & $M$ & $S D$ & $M$ & $S D$ & \\
\hline Self-concept & 120.66 & 38.13 & 151.59 & 25.04 & $34.78 * * *$ \\
\hline Self-esteem & 29.90 & 3.36 & 31.50 & 5.13 & $3.56 *$ \\
\hline Somatization & 8.26 & 5.20 & 9.85 & 6.42 & 2.13 \\
\hline Obsession-compulsion & 12.07 & 7.25 & 7.76 & 5.87 & $15.04 * * *$ \\
\hline Interpersonal sensitivity & 9.59 & 6.51 & 6.53 & 5.58 & $8.75 * *$ \\
\hline Depression & 11.00 & 8.21 & 7.91 & 7.10 & $5.51 *$ \\
\hline Anxiety & 7.40 & 7.01 & 5.07 & 5.71 & $4.66 *$ \\
\hline Hostility & 4.78 & 4.33 & 3.36 & 3.46 & $4.66 *$ \\
\hline Phobic anxiety & 2.33 & 4.09 & 1.31 & 2.24 & $4.17 *$ \\
\hline Paranoid ideation & 6.11 & 5.45 & 4.28 & 3.40 & $6.60 * *$ \\
\hline Psychoticism & 6.40 & 6.48 & 2.23 & 2.99 & $32.29 * * *$ \\
\hline Additional (melancholy depression) & 6.42 & 5.24 & 4.76 & 4.18 & $4.38 *$ \\
\hline Total Psychopathological Symptoms & 74.19 & 47.12 & 53.11 & 35.81 & $9.29 * *$ \\
\hline Global Severity Index (GSI) & 0.81 & 0.51 & 0.59 & 0.39 & $8.67 * *$ \\
\hline Positive Symptom Total (PST) & 42.38 & 20.71 & 33.46 & 18.29 & $7.02 * *$ \\
\hline Positive Symptom Distress Index (PSDI) & 1.69 & 0.50 & 1.54 & 0.63 & 1.95 \\
\hline
\end{tabular}

$* p<.05 . * * p<.01 . * * * p<.001$.

Table 2

Gender Differences in Self-Concept, Self-Esteem, and Psychopathological Symptoms in Persons with Intellectual Disability

\begin{tabular}{|c|c|c|c|c|c|c|c|}
\hline & \multicolumn{2}{|c|}{$\begin{array}{c}\text { Men + Women } \\
(n=43)\end{array}$} & \multicolumn{2}{|c|}{$\begin{array}{c}\text { Men } \\
(n=33)\end{array}$} & \multicolumn{2}{|c|}{$\begin{array}{l}\text { Women } \\
(n=9)\end{array}$} & \multirow[t]{2}{*}{$\begin{array}{l}\text { ANOVA } \\
F(1,41)\end{array}$} \\
\hline & $M$ & $S D$ & $M$ & $S D$ & $M$ & $S D$ & \\
\hline Self-concept & 120.66 & 38.13 & 124.33 & 36.42 & 107.22 & 43.44 & 1.43 \\
\hline Self-esteem & 29.90 & 3.36 & 30.27 & 3.31 & 28.56 & 3.39 & 1.88 \\
\hline Somatization & 8.26 & 5.20 & 8.45 & 5.60 & 7.55 & 3.57 & 0.20 \\
\hline Obsession-compulsion & 12.07 & 7.25 & 11.97 & 7.09 & 12.44 & 8.29 & 0.03 \\
\hline Interpersonal sensitivity & 9.59 & 6.51 & 9.15 & 6.51 & 11.22 & 6.59 & 0.71 \\
\hline Depression & 11.00 & 8.21 & 11.12 & 8.17 & 10.55 & 8.83 & 0.03 \\
\hline Anxiety & 7.40 & 7.01 & 7.60 & 6.77 & 6.66 & 8.24 & 0.12 \\
\hline Hostility & 4.78 & 4.33 & 4.45 & 3.92 & 6.00 & 5.70 & 0.89 \\
\hline Phobic anxiety & 2.33 & 4.09 & 1.90 & 3.06 & 3.88 & 6.69 & 1.68 \\
\hline Paranoid ideation & 6.11 & 5.45 & 6.24 & 5.79 & 5.66 & 4.18 & 0.07 \\
\hline Psychoticism & 6.40 & 6.48 & 6.66 & 6.52 & 5.44 & 6.63 & 0.24 \\
\hline Additional (melancholy depression) & 6.42 & 5.24 & 6.06 & 5.12 & 7.77 & 5.78 & 0.75 \\
\hline Total Psychopathological Symptoms & 74.19 & 47.12 & 73.36 & 46.92 & 77.22 & 50.60 & 0.04 \\
\hline Global Severity Index (GSI) & 0.81 & 0.51 & 0.80 & 0.52 & 0.84 & 0.54 & 0.03 \\
\hline Positive Symptom Total (PST) & 42.38 & 20.71 & 42.66 & 20.51 & 41.33 & 22.67 & 0.02 \\
\hline Positive Symptom Distress Index (PSDI) & 1.69 & 0.50 & 1.64 & 0.49 & 1.88 & 0.51 & 1.54 \\
\hline
\end{tabular}

Note: no significant differences were observed. 
Table 3

Gender Differences in Self-Concept, Self-Esteem, and Psychopathological Symptoms in Persons without Intellectual Disability

\begin{tabular}{|c|c|c|c|c|c|c|c|}
\hline & \multicolumn{2}{|c|}{$\begin{array}{c}\text { Men + Women } \\
\quad(n=128)\end{array}$} & \multicolumn{2}{|c|}{$\begin{array}{c}\text { Men } \\
(n=74)\end{array}$} & \multicolumn{2}{|c|}{$\begin{array}{l}\text { Women } \\
(n=54)\end{array}$} & \multirow[t]{2}{*}{$\begin{array}{l}\text { ANOVA } \\
F(1,126)\end{array}$} \\
\hline & $M$ & $S D$ & $M$ & $S D$ & $M$ & $S D$ & \\
\hline Self-concept & 151.59 & 25.04 & 149.04 & 25.84 & 155.41 & 23.54 & 1.79 \\
\hline Self-esteem & 31.50 & 5.13 & 31.54 & 5.18 & 31.45 & 5.09 & 0.00 \\
\hline Somatization & 9.85 & 6.42 & 9.02 & 6.05 & 11.00 & 6.79 & 2.99 \\
\hline Obsession-compulsion & 7.76 & 5.87 & 7.74 & 6.32 & 7.79 & 5.26 & 0.00 \\
\hline Interpersonal sensitivity & 6.53 & 5.58 & 6.31 & 6.19 & 6.83 & 4.66 & 0.27 \\
\hline Depression & 7.91 & 7.10 & 7.04 & 6.65 & 9.11 & 7.57 & 2.68 \\
\hline Anxiety & 5.07 & 5.71 & 4.55 & 5.24 & 5.79 & 6.28 & 1.48 \\
\hline Hostility & 3.36 & 3.46 & 3.48 & 3.88 & 3.20 & 2.81 & 0.20 \\
\hline Phobic anxiety & 1.31 & 2.24 & 1.08 & 2.06 & 1.63 & 2.45 & 1.87 \\
\hline Paranoid ideation & 4.28 & 3.40 & 4.25 & 3.70 & 4.33 & 2.99 & 0.01 \\
\hline Psychoticism & 2.23 & 2.99 & 2.04 & 3.05 & 2.50 & 2.91 & 0.73 \\
\hline Additional (melancholy depression) & 4.76 & 4.18 & 4.51 & 4.16 & 5.11 & 4.22 & 0.63 \\
\hline Total Psychopathological Symptoms & 53.11 & 35.81 & 50.05 & 37.18 & 57.31 & 33.72 & 1.28 \\
\hline Global Severity Index (GSI) & 0.59 & 0.39 & 0.55 & 0.41 & 0.63 & 0.37 & 1.28 \\
\hline Positive Symptom Total (PST) & 33.46 & 18.29 & 31.55 & 18.55 & 36.09 & 17.75 & 1.93 \\
\hline Positive Symptom Distress Index (PSDI) & 1.54 & 0.63 & 1.54 & 0.71 & 1.55 & 0.49 & 0.01 \\
\hline
\end{tabular}

Note: no significant differences were observed.

\section{Discussion}

This study had two main goals: (a) to compare selfconcept, self-esteem, and diverse psychopathological symptoms in persons with and without intellectual disability; and (b) to explore the existence of gender differences in these same variables and groups of participants.

Our results confirm that participants with mild-borderline intellectual disability, who needed intermittent support and had no diagnosed mental disorders, obtained significantly lower scores in self-concept and self-esteem. These results ratify our first hypothesis, and are in accordance with other studies that have also found poorer self-concept and selfesteem in persons with intellectual disability (Facchini, 1996; Long, 1997; Masi et al., 1999; Szivos \& Griffiths, 1990). However, they diverge from studies that have found an exaggerated appraisal of self-concept and self-esteem in persons with mild and borderline intellectual disability ( $\mathrm{Li}$ et al., 2006; Repetto \& Cifuentes, 2000).

As mentioned, the discrepancies in the results found in the studies may derive from various factors: the different research methodologies employed, the heterogeneity of the samples, or the different assessment instruments used. Another possible explanation of the results of the studies may be related to the influence of the group with which the disabled individuals are compared to evaluate of their self-concept. Much research in this area has been interpreted from the framework of the theory of social comparison. That is, self-concept depends on the characteristics of the given comparison group. It is not the same to assess self-concept in an individual who is a member of a special education group as in a person who attends a normalized educational group, because the comparison referents are different. In this sense, the findings of the study of Facchini (1996) are especially interesting. She compared three groups, one group with 104 participants with mild mental retardation, another with 139 individuals with no retardation, and a third group with 28 borderline participants who had not attended special education, although their IQ was within the range of mental retardation. The results of this study showed that selfconcept was significantly poorer in the group of persons with mild mental retardation than in the nonretarded group, and that the borderline group had a better self-concept than the group with retardation, but a poorer one than the nonretarded group. Li et al. (2006), who found higher self-concept in adults with intellectual disability compared to nondisabled persons, emphasized that this higher self-concept emerged when the participants used intragroup social comparison.

Second, in this study, we also found significantly higher scores in the remaining symptoms of the SCL-90-R (i.e., obsession-compulsion, interpersonal sensitivity, depression, anxiety, hostility, phobic anxiety, paranoid ideation, psychoticism, and in melancholy depression, as well as in the Total Psychopathological Symptoms, the Global Severity Index, and the Positive Symptom Total). 
Therefore, our results support the works of authors who found that people with intellectual disability have higher scores in psychopathological symptoms (Bouras \& Drummond, 1992; Cowley et al., 2004; LaMalfa et al., 1997; Slone et al., 1999). Specifically, studies have found that these persons have higher incidence of anxiety disorders (Cowley et al.; LaMalfa et al.; Masi et al., 1999; Matson, Anderson, \& Bamburg, 2000), depressive disorders (Cowley et al.; Lunsky, 2003; Masi et al.), a tendency to isolate themselves (LaMalfa et al.), and schizophrenia (Bouras \& Drummond; Cowley et al.). Thus, these results confirm our second hypothesis.

With regard to these results, Matson and colleagues (2000) indicate various factors that could explain why youths and adults with mild-borderline intellectual disability exhibit higher incidence of this kind of disorders, not only in comparison with people with no intellectual disability, but also in comparison with people with moderate or severe intellectual disability. Among these factors, the following are noteworthy: (a) the criteria used for the general population may also be more easily applied in the case of less severe intellectual disabilities; (b) the people with this kind of disabilities often have the necessary linguistic skills to respond to questions related to internal stimuli and subjective questions; and (c) the people from this population are more aware of being stigmatized or of being treated differently, so it is more likely for them to develop anxiety or mood disorders.

Third, we found no gender differences in self-concept and self-esteem in the two groups studied. These results confirm our third hypothesis, which stated that no such gender differences would be found and which are coherent with the results from other studies (Facchini, 1996; Garaigordobil et al., 2005; Lameiras \& Rodríguez, 2003), although they disagree with the work of Wilgenbush and Merrel (1999). The differences with the study of these researchers may be due to the lower age level of the participants of their sample (children and adolescents).

Lastly, no gender differences were found in psychopathological symptoms in the nonretarded group, which contradicts the results of other studies (González de Rivera et al., 2002). Nor did we find differences between men and women in the intellectually disabled group. Therefore, our fourth hypothesis, which posited that women from both groups, regardless of whether or not they were intellectually disabled, would score higher in psychopathological symptoms, is rejected. Perhaps an explanation of the discrepancy with the results of the study of González de Rivera et al. is the higher level of studies in the participants of their sample in comparison with the sample used in this work, in which people with higher or university studies were not included. Some exploratory analyses carried out with other samples (Garaigordobil, in press) have led to the observation that the higher the educational level achieved, the larger the differences between men and women in psychopathological symptoms, with women scoring higher than men. Within the analysis of gender differences, the small number of women with intellectual disability included in the sample of this study is striking; there were significant differences between the number of men and women with intellectual disability, but these differences are also observed in sociodemographic studies on intellectual disability (Instituto Nacional de Estadística [INE], 2000; IMSS, 2003), which reveals the existence of more disabled men $(62 \%)$ than women $(38 \%)$. Regarding this, we emphasize that the problem with these prevalence data may lie in the fact that the male population, which is more active in the work market and more socially visible, is also more prone to having this disability easily recognized.

In general terms, the data of this study reveal that persons with mild-borderline intellectual disability, in comparison with the general population, present lower scores in self-concept-self-esteem, and are more likely to develop diverse psychopathological disorders. The results of this study have educational implications and suggest the importance of implementing programs, during infancy and adolescence, to promote self-concept and self-esteem in persons who present difficulties in their intellectual development during the early school years. As mild-borderline disability is a risk factor associated with the presence of psychopathology, at the assistential level, we emphasize the need to provide adequate services to assess and treat people with mild-borderline intellectual disability, ensuring that they do not end up in "no man's land" between the general mental health services and the services dedicated to more profound intellectual disability.

This work identifies an area of inconsistency that requires more exhaustive study, which refers to the nature of the interactions between self-concept-self-esteem and psychopathological symptoms. A study with a larger sample of the population with intellectual disability would very likely help to clarify this issue.

\section{References}

American Association on Mental Retardation. (1992). Mental retardation: Definition, classification and systems of supports ( $9^{\text {th }}$ ed.). Washington, DC: Author.

Borthwick-Duffy, S. (1994). Epidemiology and prevalence of psychopathology in people with mental retardation. Journal of Consulting and Clinical Psychology, 62, 27-17.

Bouras, N., \& Drummond, C. (1992). Behaviour and psychiatric disorders of people with mental handicaps, living in the community. Journal of Intellectual Disability Research, 36, 349-357. 
Clay, J., \& Thomas, J. C. (2005). Prevalence of Axis I psychopathology in an intellectually disabled population: Type of pathology and residential supports. Journal of Developmental and Physical Disabilities, 17, 75-84.

Cowley, A., Holt, G., Bouras, N., Sturmey, P., Newton, J.T., \& Costello, H. (2004). Descriptive psychopathology in people with mental retardation. Journal of Nervous and Mental Disease, 192, 232-237.

De las Cuevas, C., \& González de Rivera, J.L. (1991). Perfil sintomático y diagnóstico en pacientes psiquiátricos ambulatorios. Psiquis, 12, 326-336.

Derogatis, L.R., Rickels, K., \& Rock, A.F. (1976). The SCL-90 and the MMPI: A step in the validation of a new self-report scale. British Journal of Psychiatry, 128, 280-289.

Derogatis, L. R., \& Cleary, (1977). Confirmation of the dimensional structure of the SCL-90: A study in construct validation. Journal of Clinical Psychology, 33, 981-989.

Derogatis, L.R. (1983). SCL-90-R, Administration, scoring and procedures Manual II for the Revised Version of the SCL-90. Baltimore: Johns Hopkins University Press. (Spanish translation: SCL-90-R. Cuestionario de 90 síntomas revisado. Madrid: TEA, 2002).

Dosen, A. (1993). Diagnosis and treatment of psychiatric and behavioural disorders in mentally retarded individuals: The state of the art. Journal of Intellectual Disability Research, 37, 1-7.

Facchini, R.L. (1996). Self-esteem in young adults with mild mental retardation. Dissertation Abstracts International: Section B: The Sciences and Engineering, 56(10-B), 5793.

Garaigordobil, M., Durá, A., \& Pérez, J.I. (2005). Psychopathological symptoms, behavioural problems, and selfconcept/self-esteem: A study with adolescents from 14 to 17 years. Annuary of Clinical and Health Psychology, 1, 53-63.

Garaigordobil, M. (in press). LAEA. Listado de adjetivos para la evaluación del autoconcepto en adolescentes y adultos. Madrid: Pirámide.

García, F., \& Musitu, G. (1999). AF-5. Autoconcepto Forma 5. Madrid: TEA.

González de Rivera, J.L., De las Cuevas, C., Rodríguez Abuín, M., \& Rodríguez Pulido, F. (2002). SCL-90-R, Symptom Checklist 90 Revised, adaptación española. Madrid: TEA.

Gresham, F.M., \& MacMillan, D.L. (1997). Social competence and affective characteristics of students with mild disabilities. Review of Educational Research, 67, 377-415.

Hurley, A., Folstein, M.D., \& Lam, N. (2003). Patients with and without intellectual disability seeking outpatient psychiatric services: Diagnoses and prescribing pattern. Journal of Intellectual Disability Research, 47, 39-50.

Instituto de Migraciones y Servicios Sociales. (2003). Personas con discapacidad intelectual y necesidad de apoyos intermitentes: Situación, necesidades y demandas. Madrid: Ministerio de Trabajo y Asuntos sociales, Instituto de Migraciones y Servicios Sociales.

Instituto Nacional de Estadística. (2000). Encuesta sobre discapacidades, deficiencias y estados de salud 1999, Madrid, INE. Madrid: Author.
LaMalfa, G., Notarelli, A., Hardoy, M.C., Bertelli, M., \& Cabras, P.L. (1997). Psychopathology and mental retardation: An Italian epidemiological study using the PIMRA. Research in Developmental Disabilities, 18, 179-184.

Lameiras, M., \& Rodríguez, Y. (2003). Age and sex differences in self-esteem among Spanish adolescents. Psychological Reports, 93, 876-878.

Li, E. P-Y., Tam, A. S-F., \& Man, D. W-K. (2006). Exploring the self-concepts of persons with intellectual disabilities. Journal of Intellectual Disabilities, 10, 19-34.

Long, C.A. (1997). The development of self-esteem in young adolescents with mild mental retardation. Dissertation Abstracts International Section A: Humanities and Social Sciences, 57(9A), 3892.

Luckasson, R., Borthwick-Duffy, S., Buntix, W.H.E., Coulter, D.L., Craig, E.M., Reeve, A., Schalock, R.L., Snell, M.E., Spitalnik, D.M., Spreat, S., \& Tasse, M.J. (Eds.). (2002). Mental retardation. Definition, classification and systems of supports (10 th ed.). Washington DC: American Association on Mental Retardation.

Lunsky, Y. (2003). Depressive symptoms in intellectual disability: Does gender play a role? Journal of Intellectual Disability Research 47, 417-427.

Masi, G., Mucci, M., Favilla, L., \& Poli, P. (1999). Dysthymic disorder in adolescents with intellectual disability. Journal of Intellectual Disability Research, 43, 80-87.

Matson, J.L., Anderson, S.J., \& Bamburg, J.W. (2000). The relationship of social skills to psychopathology for individuals with mild and moderate mental retardation. British Journal of Developmental Disabilities, 46, 15-22.

McCarthy, J.D., \& Hoge, D.R. (1982). Analysis of age effects in longitudinal study of adolescent self-esteem. Developmental Psychology, 18, 372-379.

Nezu, C., Nezu, A., \& Gill-Weiss, M. (1992). Psychopathology in persons with mental retardation. Champaign, IL: Research Press Company.

Repetto, E., \& Cifuentes, M.E. (2000). Algunos rasgos significativos para el desarrollo de las habilidades sociales en adolescentes con deficiencia mental leve. Estudio de casos. Revista Española de Orientación y Psicopedagogía, 11, 213-228.

Rojahn, J., \& Tasse, M.J. (1996). Psychopathology in mental retardation. In J.W. Jacobson \& J.A. Mulick (Eds.), Manual of diagnosis and professional practice in mental retardation (pp. 147-156). Washington DC: American Psychological Association.

Rosenberg, M. (1965). Society and the adolescent self-image. Princeton, NJ: Princeton University Press.

Silber, E., \& Tippett, J. (1965). Self-esteem: Clinical assessment and measurement validation. Psychological Reports, 16, 1017-1071.

Sinanson, V. (1992). Mental handicap and the human condition. London: Free Association Books.

Slone, M., Durrheim, K., Kaminer, D., \& Lachman, P. (1999). Issues in the identification of comorbidity of mental retardation and psychopathology in a multicultural context. Social Psychiatry and Psychiatric Epidemiology, 34, 190-194. 
Szivos, S.E., \& Griffiths, E. (1990). Group processes involved in coming to terms with a mentally retarded identity. Mental Retardation, 23, 333-341.

Verdugo, M.A. (2003). Análisis de la definición de discapacidad intelectual de la Asociación Americana sobre Retraso Mental de 2002. Siglo Cero 34, 5-19.

Wilgenbush, T., \& Merrel, K.W. (1999). Gender differences in selfconcept among children and adolescents: A meta-analysis of multidimensional studies. School Psychology Quarterly, 14, 101-120.
World Health Organization. (2001). International classification of functioning, disability and health. Geneva: Author. (Spanish translation: Clasificación internacional del funcionamiento, de la discapacidad y de la salud: CIF. Madrid: Ministerio de Trabajo y Asuntos Sociales, Instituto de Migraciones y Servicios Sociales, 2001.)

Received October 4, 2006 Revision received January, 16, 2007 Accepted January 24, 2007 